\title{
Relationships between reproductive traits of heifers and cows and yield traits for Holsteins in Japan
}

\author{
H. Abe, Y. Masuda, and M. Suzuki ${ }^{1}$ \\ Department of Life Science and Agriculture, Obihiro University of Agriculture and Veterinary Medicine, Obihiro, 080-8555, Japan
}

\begin{abstract}
The objective of this study was to investigate relationships between reproductive traits in heifers and cows and yield traits for Holsteins in Japan. Insemination and lactation records for cows calved between 1990 and 2003 in Hokkaido region were obtained. Age at first service, age at conception, and conception rate for first service were calculated for heifers. Days from calving to first service, days open, and conception rate for first service were calculated for first- and second-parity cows. The yield traits used were 305-d milk, fat, and protein yields. A threshold animal model was applied for the conception rate for first service, and a linear animal model was applied for the other traits. Single-trait and 2 -trait genetic analyses were performed by the Bayesian method using Gibbs sampling. Heritability estimates ranged from 0.027 to 0.051 for conception rate for first service, and from 0.074 to 0.128 for the other reproductive traits. If the relationships of other traits were not considered, days from calving to first service was favorable to genetic selection for reproductive traits because of relatively high heritability and because it can be available earlier than the days open. Genetic correlations among reproductive traits were high, especially in cows. The genetic correlations between reproductive traits for heifers and those for cows were lower than the genetic correlations between reproductive traits for first parity and those of second parity, suggesting that reproductive traits for heifers should be evaluated separately from reproductive traits for cows. Genetic correlations between yield and reproductive traits in cows were antagonistic. In contrast, genetic correlations between reproductive traits for heifers and yield traits were slightly desirable. Depending on the reporting rate of insemination records for heifers and the results of investigations for relationships with productive maturity, selection by reproductive traits for heifers will enable the improvement of reproductive performance without a loss in genetic progress for yield traits.
\end{abstract}

Received November 13, 2008.

Accepted March 17, 2009.

${ }^{1}$ Corresponding author: mit@obihiro.ac.jp
Key words: reproductive trait, yield trait, virgin heifer, genetic correlation

\section{INTRODUCTION}

For dairy cows, good reproductive performance is very important to improve lifetime productivity. Currently, many countries perform genetic evaluation for reproductive traits, and Interbull regularly publishes international sire evaluations of these traits (International Bull Evaluation Service, 2008). Generally, the reproductive traits are represented by the interval between 2 reproductive events or a score related to success or failure to insemination, which are calculated from insemination and calving records. Conception rate for first service (CR), which shows success or failure of first insemination, is a performance indicator for conception. Days from calving to first service (DFS) and days open (DO), which are categorized as interval traits, are performance indicators for return to estrus, and for return to estrus and conception, respectively. Heritability estimates for interval traits are generally higher than that of $\mathrm{CR}$, but the interval traits are strongly influenced by management practices.

In Japan, in response to increased attention to functional traits, genetic evaluation for some functional traits has begun (National Livestock Breeding Center, 2007), but genetic evaluation for reproductive traits has not, and there are very few studies of genetic analysis for reproductive traits in Japan (Atagi and Hagiya, 2005; Abe et al., 2008). Specifically, no genetic analysis of reproductive traits for virgin heifers has been done. Phenotypic trends of DFS and DO showed a deterioration in these traits (Abe et al., 2008), suggesting that genetic analysis for reproductive traits is necessary for Japan.

Numerous researchers have reported antagonistic genetic correlations between reproductive traits in cows and yield traits (Dematawewa and Berger, 1998; HaileMariam et al., 2003; Kadarmideen et al., 2003; Abe et al., 2008). Although heritabilities for reproductive traits are generally low, genetic selection for yield traits causes an undesirable correlated response in reproductive traits. Against this background, the number of 
countries that have included reproductive traits into the total merit index has been increasing (International Bull Evaluation Service, 2008). In contrast, studies on reproductive traits for virgin heifers reported slightly desirable genetic correlation with yield traits (Hansen et al., 1983; Muir et al., 2004; Andersen-Ranberg et al., 2005). In addition, there are few studies on betweenparity analyses for reproductive traits (Haile-Mariam et al., 2003), or on genetic correlations of reproductive traits between virgin heifers and cows (AndersenRanberg et al., 2005; Jamrozik et al., 2005; Kuhn et al., 2006).

In Hokkaido, Japan, collection of insemination records started in the early 1980s. Reporting of insemination records for virgin heifers has not been required, but about half of the cows have such records. The objective of this study was to investigate relationships between reproductive traits in heifers and cows and yield traits for Holsteins in Japan.

\section{MATERIALS AND METHODS}

Data used were insemination and lactation records for cows calved between 1990 and 2003 in Hokkaido, Japan, collected by the Hokkaido Dairy Milk Recording and Testing Association, and pedigree records collected by the Holstein Cattle Association of Japan (Hokkaido Branch).

In Japan, Holsteins are crossed with Japanese Blacks for a variety of purposes, such as to decrease calving difficulty for heifers or to adjust the number of offspring, so it is difficult to separate the influence of insemination of Japanese Black from that of management policy. Additionally, this study was aimed at the genetic improvement of reproductive traits only for the dairy cattle population, so the insemination records of Japanese Black sires were not treated separately from those of Holstein sires.

Age at first service (AFS), age at conception (AC), and CR were calculated for heifers; and DFS, DO, and CR were calculated for first- and second-parity cows. The reporting of pregnancy diagnosis is not required in Japan, so reproductive traits were calculated for parities whose calving date of next parity was reported. An insemination record within $10 \mathrm{~d}$ after a previous insemination was considered as double insemination, and was deleted. Conception rate was coded as 1 if only one insemination was reported, or 0 otherwise.

Yields (305-d) of milk, fat, and protein were extracted as yield traits from lactation records. If the last DIM $\geq 305$, total yield until 305 DIM was used, and if 240 $\leq$ last DIM $<305$, lactation yield was used. Only the records under twice-a-day milking were used.
The records of cows that had no date of first calving, had no sire identification, moved to a different herd, or whose birth date did not match with calving date of their dams were eliminated. The records that included abortion or embryo donor, or whose days open were different from days open predicted from calving interval with standard gestation length $(280 \mathrm{~d})$ by over $14 \mathrm{~d}$ were deleted. For the yield traits, the records within the range of \pm 3 standard deviation units from the overall mean were retained. The records that matched the following criteria were retained: AFS between 321 and 1,082 d; DFS between 21 and $200 \mathrm{~d}$; DO between 21 and $410 \mathrm{~d}$; number of services between 1 and 10; age at first calving between 20 and $43 \mathrm{mo}$; and age at second calving between 32 and 59 mo. At least one contemporary record must have been in the herd-year of first-service subclass for heifers, and herd-year of calving subclass for cows.

The resulting numbers of records of reproductive traits for heifers, reproductive traits for first parity, yield traits for first-parity cows, reproductive traits for second-parity cows, and yield traits for secondparity cows were $308,238,626,899,710,980,490,265$, and 578,921 , respectively. Percentages of edited records from original records ranged from 62.7 to $65.8 \%$.

Genetic parameters were estimated by single-trait analyses, 2-trait analyses among reproductive traits, and 2-trait analysis between reproductive and yield traits. Because of the limitation of computing time, subsets of records were extracted by random sampling of herds. The numbers of records in subsets were about 400,000 and 200,000 for single-and 2-trait analyses, respectively. The pedigree records were traced back 3 generations. The numbers of animals in the resultant pedigree file ranged from 669,022 to 764,534 for singletrait analyses, and from 370,138 to 442,702 for 2-trait analyses, respectively.

A threshold animal model was applied for CR, and a linear animal model was applied for the other traits. The following model was applied to AFS and AC:

$$
y_{i j k}=h f y_{i}+F Y M_{j}+a_{k}+e_{i j k},
$$

where $y_{i j k}$ is the observation; $h f y_{j}$ is random effect of $i$ th herd-year of first service; $F Y M_{j}$ is fixed effect of $j$ th month-year of first service; $a_{k}$ is random additive genetic effect of animal $k$; and $e_{i j k}$ is random error term.

The model for CR in heifers was

$$
y_{i j k l}=h f y_{i}+F Y M_{j}+F A_{k}+a_{l}+e_{i j k l},
$$

where $h f y_{i}, F Y M_{j}, a_{l}$, and $e_{i j k l}$ are as in the previous model; $y_{i j k l}$ is unobserved liability for CR; and $F A_{k}$ is 
Table 1. Descriptive statistics of reproductive traits for heifers

\begin{tabular}{lrrr}
\hline Trait & Records & Mean & \multicolumn{1}{c}{ SD } \\
\hline Age at first service (d) & 308,238 & 518.6 & 84.8 \\
Age at conception (d) & 308,238 & 545.0 & 102.6 \\
Conception rate for first service (\%) & 308,238 & 69.0 & 46.2 \\
\hline
\end{tabular}

fixed effect of $k$ th age group of first service. The age groups of first service were $\leq 14,15,16,17,18$, and $\geq 19$ mo.

For cow traits, the following model was applied:

$$
y_{i j k l}=h y_{i}+C Y M_{j}+C A_{k}+a_{l}+e_{i j k l},
$$

where $y_{i j k l}, a_{l}$, and $e_{i j k l}$ are as in the previous model; $h y_{i}$ is random effect of $i$ th herd-year of calving; $C Y M_{j}$ is fixed effect of $j$ th year-month of calving; and $C A_{k}$ is $k$ th age group of calving. Each age group of calving contained 4 mo for both parities. For example, the age group 1 of first calving contained cows from 20 to $23 \mathrm{mo}$, and the age group 1 of second calving contained cows from 32 to 35 mo. In a preliminary study, an adjustment of yield traits by DO did not affect the genetic parameter estimates, so the yield traits were not adjusted.

For within-parity analyses, only animals that had both records were used. For across-parity analyses, missing records were allowed for later parity. In matrix notation, a 2-trait model is written as

$$
\mathbf{y}=\mathbf{X b}+\mathbf{Z}_{1} \mathbf{h y}+\mathbf{Z}_{2} \mathbf{a}+\mathbf{e}
$$

where $\mathbf{y}$ is the vector of observations or liabilities; $\mathbf{b}$ is the vector of fixed effects; hy is the vector of management group effects; $\mathbf{a}$ is the vector of random additive genetic effects; $\mathbf{e}$ is the vector of random errors; and $\mathbf{X}$, $\mathbf{Z}_{1}$, and $\mathbf{Z}_{2}$ are design matrices. For the random effects, the following (co)variance structures were assumed:

$$
\text { hy } \sim N\left(\mathbf{0}, \mathbf{H}_{0} \otimes \mathbf{I}\right), \mathbf{a} \sim N\left(\mathbf{0}, \mathbf{G}_{0} \otimes \mathbf{A}\right), \mathbf{e} \sim N\left(\mathbf{0}, \mathbf{R}_{0} \otimes \mathbf{I}\right),
$$

where

$$
\begin{gathered}
\mathbf{H}_{0}=\left[\begin{array}{cc}
\sigma_{h y 1}^{2} & \sigma_{h y 1 h y 2} \\
\sigma_{h y 2 h y 1} & \sigma_{h y 2}^{2}
\end{array}\right], \\
\mathbf{G}_{0}=\left[\begin{array}{cc}
\sigma_{a 1}^{2} & \sigma_{a 1 a 2} \\
\sigma_{a 2 a 1} & \sigma_{a 2}^{2}
\end{array}\right], \\
\text { and } \mathbf{R}_{0}=\left[\begin{array}{cc}
\sigma_{e 1}^{2} & \sigma_{e 1 e 2} \\
\sigma_{e 2 e 1} & \sigma_{e 2}^{2}
\end{array}\right]
\end{gathered}
$$

are the (co)variance matrices of management group, additive genetic, and residual effects, respectively, and $\mathbf{A}$ is the additive relationship matrix; $\mathbf{I}$ is the identity matrix; and $\otimes$ is the operator for Kronecker product. For across-parity analysis, $\sigma_{h y 1 h y 2}$ was set to zero. For $\mathrm{CR}$, residual variance was set to 1 on the liability scale. The management group and additive genetic effects were assumed to be independent.

The THRGIBBS1F90 program (Tsuruta and Misztal, 2006) was used to perform Gibbs sampling. Flat prior was used for the fixed effects, and inverse Wishart distribution with minimum degree of belief was used as prior for the random effects. Length of Gibbs chain was 200,000, and the first 50,000 samples were discarded as burn-in, which were determined based on visual inspection of trace plots of selected parameters. Thinning interval was set to 50, and the resulting 3,000 samples were used for calculating posterior means.

\section{RESULTS AND DISCUSSION}

\section{Descriptive Statistics}

Tables 1 and 2 show descriptive statistics of heifer and cow traits, respectively, which were calculated for subsets used in single-trait analyses. The mean CR in heifers was higher than in cows, partly because heifers were not affected by lactation and because of less accurate insemination records (e.g., only the last insemination record was reported).

Table 2. Descriptive statistics of reproductive and yield traits for cows

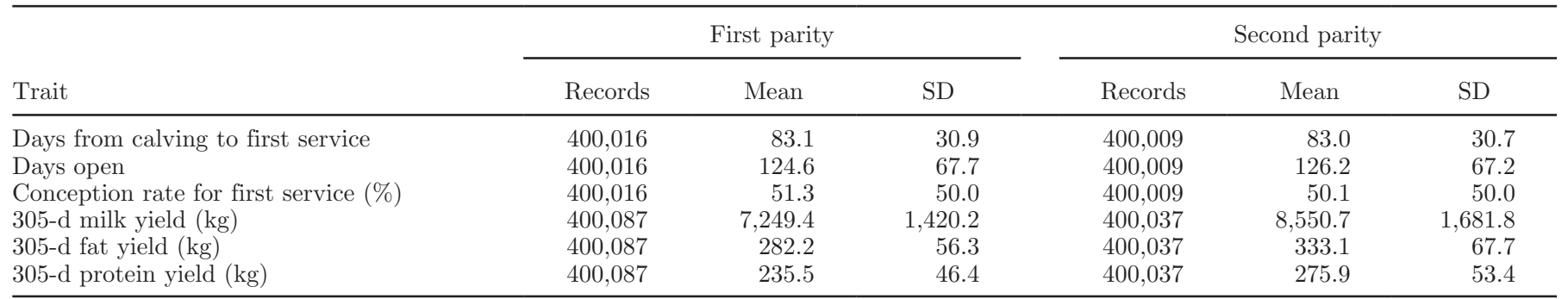




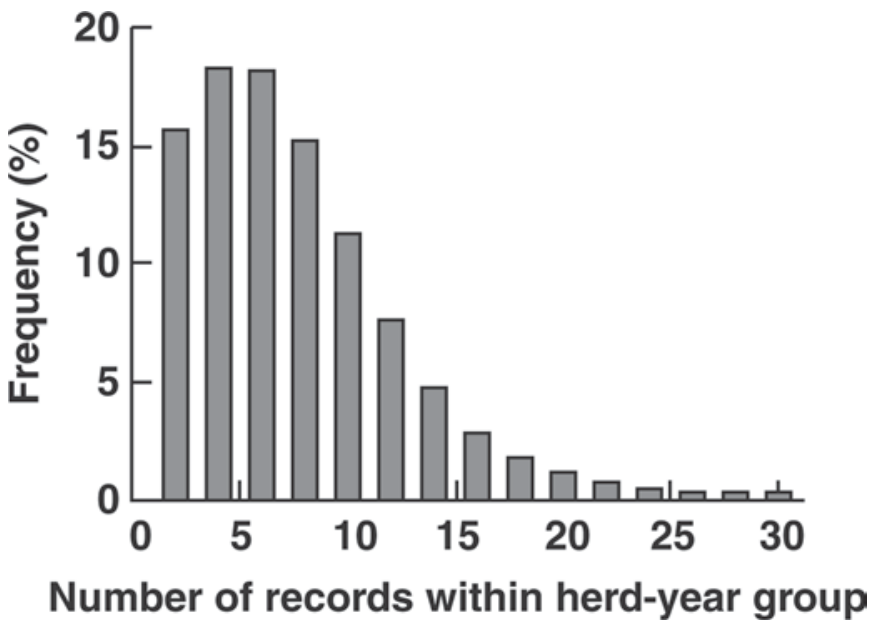

Figure 1. Histogram of the number of records within herd-year group for the subset used in single-trait analysis of conception rate for first parity.

Descriptive statistics of reproductive traits by year of calving are shown in Table 3 . The means for CR tended to decrease over time, and the means for DFS and DO tended to increase until 1998 and 2001, respectively, suggesting that reproductive traits have been deteriorating over time. The means for DFS and DO slightly decreased in recent years, the cause of which is not clear. However, these values are still higher than those in the early 1990s, so investigating genetic improvements of reproductive traits remains important. On the other hand, the means for AFS and AC have been decreasing, which indicates a tendency for early sexual maturity or earlier first service.

Figure 1 shows a histogram of the number of records within herd-year group for the subset used in single-trait analysis of CR for first parity. Over $60 \%$ of the herds are small, so, as described by Oikawa and Sato (1997), it was appropriate to treat the management group effect as random not only for the threshold model, but also for the linear model.

\section{Heritabilities}

Table 4 shows genetic parameters estimated from single-trait analyses. The heritability estimates of CR were $<0.1$, with the estimate for heifers lower than that for cows. These results agree with heritability estimates of 56-d nonreturn rate by Jamrozik et al. (2005). The heritability estimate of AFS was 0.128, which was similar to the estimate of Jamrozik et al. (2005) and slightly higher than the estimate of Hansen et al. (1983). The heritability of AC was estimated to be 0.120 , which was slightly lower than that reported by Hansen et al. (1983). These heritabilities were the highest in reproductive traits. However, the reporting rate of insemination records for heifers is around 50\%, and these traits are expected to be closely related to early productive maturity, so it is thought to be too early to make selection by these traits.

The heritabilities of DO were estimated to be around 0.09 and were slightly higher than those in other reports (Dematawewa and Berger, 1998; Kadarmideen et al., 2003; Atagi and Hagiya, 2005; Abe et al., 2008). Also, the heritabilities of DFS were slightly higher than the estimates listed above, but agreed with the estimate of Jamrozik et al. (2005). These results stemmed from differences in the treatment of management group effects. By assigning management group effects as random, the heritability estimates of reproductive traits rose slightly. There are many small farms in Japan (Figure 1 ), so treating the management group effects as fixed may bring on an extreme category problem (Harville and Mee, 1984). Therefore, the management group effects should be treated as random.

Judging from the heritability estimates and computing time, interval traits seem to be effective for genetic improvement of reproductive traits. This study used records in which calving date of next parity is reported, but pregnancy diagnosis and calving date of next parity are unnecessary for DFS. Depending on data availability and appropriate data editing criteria, DFS might be more suitable for genetic evaluation than DO.

Table 3. Means for reproductive traits ${ }^{1}$ by year of calving and parity

\begin{tabular}{|c|c|c|c|c|c|c|c|c|c|}
\hline Year of calving & \multicolumn{3}{|c|}{ Heifer $^{2}$} & \multicolumn{3}{|c|}{ First parity } & \multicolumn{3}{|c|}{ Second parity } \\
\hline 1990 to 1992 & 530.3 & 548.0 & 77.6 & 80.3 & 113.4 & 57.8 & 79.8 & 113.1 & 57.1 \\
\hline 1996 to 1998 & 526.6 & 553.6 & 68.9 & 84.5 & 127.0 & 50.1 & 83.8 & 127.6 & 49.4 \\
\hline 1999 to 2001 & 505.3 & 535.1 & 64.6 & 84.0 & 131.6 & 46.5 & 84.5 & 135.1 & 44.6 \\
\hline 2002 to 2003 & 496.4 & 530.6 & 62.7 & 82.7 & 129.8 & 46.8 & 83.7 & 134.4 & 44.3 \\
\hline
\end{tabular}

${ }^{1} \mathrm{AFS}=$ age at first service; $\mathrm{AC}=$ age at conception; $\mathrm{CR}=$ conception rate for first service; $\mathrm{DFS}=$ days from calving to first service; $\mathrm{DO}=$ days open.

${ }^{2}$ Year of first calving was used for partitioning of records. 
Table 4. Estimates of herd-year $\left(\sigma_{h y}^{2}\right)$, additive genetic $\left(\sigma_{a}^{2}\right)$, and residual $\left(\sigma_{e}^{2}\right)$ variances, and heritability $\left(h^{2}\right)$ from single-trait analysis, with posterior standard deviations in parentheses

\begin{tabular}{|c|c|c|c|c|c|c|c|c|c|}
\hline$\frac{\text { Parity }}{\text { Heifer }}$ & $\frac{\text { Trait }^{1}}{\text { AFS }^{2}}$ & \multicolumn{2}{|c|}{$\sigma_{h y}^{2}$} & \multicolumn{2}{|c|}{$\sigma_{a}^{2}$} & \multicolumn{2}{|c|}{$\sigma_{e}^{2}$} & \multicolumn{2}{|c|}{$h^{2}$} \\
\hline & $\mathrm{AC}^{2}$ & 3.893 & $(0.004)$ & 1.254 & $(0.005)$ & 5.326 & $(0.003)$ & 0.120 & $(0.004)$ \\
\hline & $\mathrm{CR}$ & 0.101 & $(0.003)$ & 0.030 & $(0.004)$ & $1.000^{4}$ & & 0.027 & $(0.003)$ \\
\hline & $\mathrm{DO}^{2}$ & 0.251 & $(0.001)$ & 0.413 & $(0.002)$ & 3.904 & $(0.002)$ & 0.090 & $(0.005)$ \\
\hline & $\mathrm{CR}$ & 0.076 & $(0.002)$ & 0.058 & $(0.006)$ & $1.000^{4}$ & & 0.051 & $(0.005)$ \\
\hline & MILK $^{3}$ & 0.733 & $(0.006)$ & 0.559 & $(0.008)$ & 0.670 & $(0.005)$ & 0.285 & $(0.004)$ \\
\hline \multirow[t]{6}{*}{ Second } & $\mathrm{DFS}^{2}$ & 0.118 & $(0.000)$ & 0.101 & $(0.001)$ & 0.726 & $(0.000)$ & 0.107 & $(0.006)$ \\
\hline & $\mathrm{DO}^{2}$ & 0.161 & $(0.000)$ & 0.328 & $(0.002)$ & 3.924 & $(0.002)$ & 0.074 & $(0.005)$ \\
\hline & $\mathrm{CR}$ & 0.076 & $(0.002)$ & 0.055 & $(0.006)$ & $1.000^{4}$ & & 0.049 & $(0.005)$ \\
\hline & MILK $^{3}$ & 1.055 & $(0.009)$ & 0.631 & $(0.011)$ & 1.021 & $(0.007)$ & 0.233 & $(0.004)$ \\
\hline & $\mathrm{FAT}^{2}$ & 1.635 & $(0.001)$ & 0.925 & $(0.002)$ & 1.527 & $(0.001)$ & 0.226 & $(0.004)$ \\
\hline & $\mathrm{PRO}^{2}$ & 1.244 & $(0.001)$ & 0.447 & $(0.001)$ & 0.936 & $(0.001)$ & 0.170 & $(0.003)$ \\
\hline
\end{tabular}

${ }^{1} \mathrm{AFS}=$ age at first service; $\mathrm{AC}=$ age at conception; $\mathrm{CR}=$ conception rate for first service; $\mathrm{DFS}=$ days from calving to first service; $\mathrm{DO}=$ days open; MILK $=305$-d milk yield; FAT $=305$-d fat yield; $\mathrm{PRO}=305$-d protein yield .

${ }^{2}$ Each value (other than $h^{2}$ ) has been divided by $10^{3}$.

${ }^{3}$ Each value (other than $h^{2}$ ) has been divided by $10^{6}$.

${ }^{4}$ Residual variances were set to 1 .

However, the heritabilities for reproductive traits were not as high as those for yield traits, so it is difficult to obtain breeding values with high accuracy. Therefore, the efficiency of genetic improvement is expected to be low, but by incorporating reproductive traits in the total merit index, genetic deterioration for reproductive traits will be partially mitigated.

\section{Relationships Among Reproductive Traits}

Table 5 shows genetic and phenotypic correlations among reproductive traits. Residual correlations were also calculated, and in across-parity analyses, these correlations were $<0.1$ in absolute value. Among heifer traits, AC was closely related genetically and phenotypically to AFS and CR but the genetic and phenotypic correlations between CR and AFS were -0.11 and 0.05 , respectively, which were very low. These results suggest that earlier first service without loss in CR would be possible with optimum timing of insemination.

Although the genetic correlation between DO and DFS and the genetic correlation between DO and CR in first parity and those in second parity were generally high, lower estimates were obtained between DFS and CR $(-0.24$ in first parity, and -0.25 in second parity). A similar tendency was observed in phenotypic correlations.

The genetic and phenotypic correlations estimated in this study agree with the results of Kadarmideen et al. (2003). The results support the following assumption: DO indicates "performance for return to estrus and conception," whereas DFS indicates "performance for return to estrus" and CR indicates "performance for conception." Consequently, in evaluation of reproductive traits in cows, simultaneous evaluation of CR and DFS might be more favorable than evaluation of DFS only.

The genetic correlation of $\mathrm{CR}$ in heifers with $\mathrm{CR}$ in first parity and CR in second parity were 0.74 and 0.69 , respectively, and were lower than the genetic correlation of CR between first and second parity (0.97). The genetic correlations of AFS or AC with reproductive traits in cows ranged from -0.27 to 0.24 , which were not as high as genetic correlations of CR between heifers and cows. This is partly because heifer traits are not affected by lactation. Andersen-Ranberg et al. (2005) estimated genetic correlation of nonreturn rate in heifers with nonreturn rate in cows and DFS as 0.54 and 0.24 , respectively. Jamrozik et al. (2005) reported genetic correlation of 0.60 between nonreturn rate in heifers and cows. Kuhn et al. (2006) reported genetic correlation of 0.39 between CR in heifers and cows. The results in this study basically support their results, suggesting that reproductive traits in heifers and cows should not be considered as the same traits. Low reporting rate of insemination records for heifers, however, might affect such results to some degree. Considering that using heifer data is advantageous for being less exposed for selection due to fertility, it is strongly recommended to increase the reporting rate of insemination records for heifers.

The estimated genetic correlations between reproductive traits in heifers and cows were generally desirable, indicating that selection of reproductive traits in heif- 
Table 5. Genetic (upper diagonal) and phenotypic ${ }^{1}$ (lower diagonal) correlations of reproductive traits in heifers and cows, with posterior standard deviations in parentheses

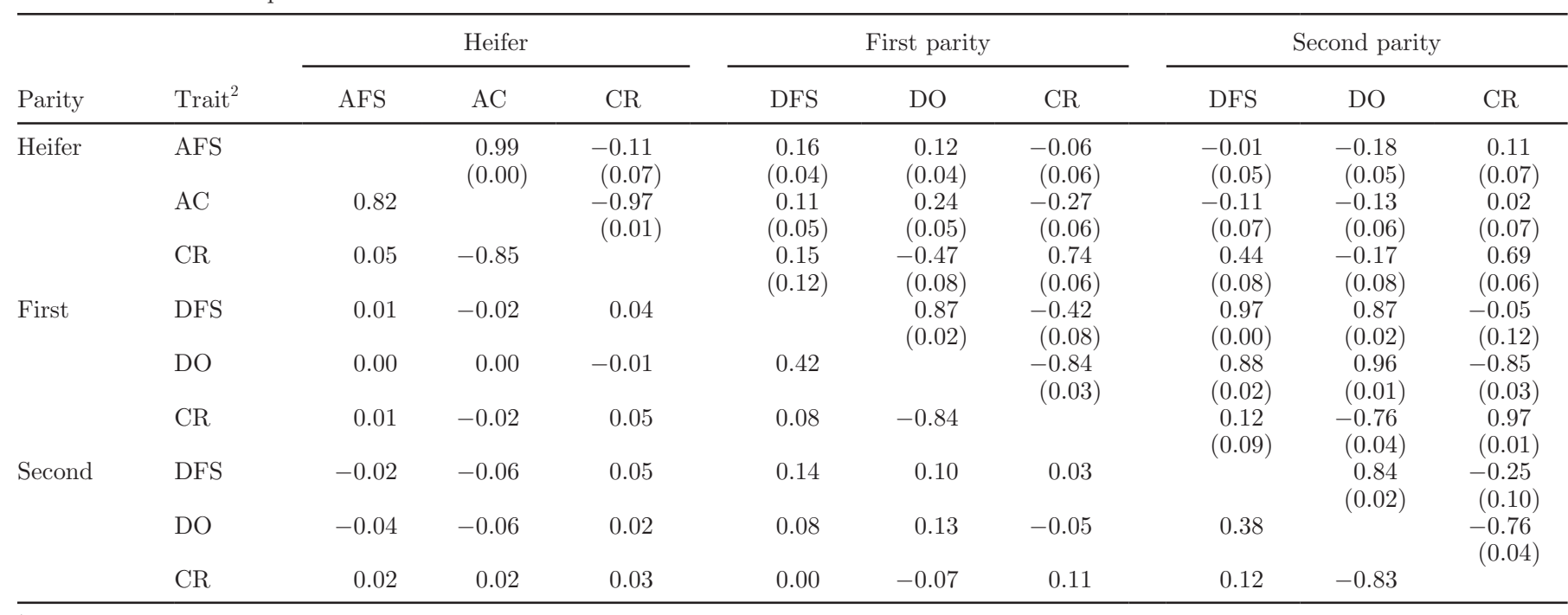

${ }^{1}$ All posterior standard deviations for phenotypic correlation estimates were $<0.01$.

${ }^{2} \mathrm{AFS}=$ age at first service; $\mathrm{AC}=$ age at conception; $\mathrm{CR}=$ conception rate for first service; $\mathrm{DFS}=$ days from calving to first service; $\mathrm{DO}=$ days open.

ers may improve reproductive performance during their lifetime. However, because reproductive traits in heifers appear to be closely associated with early productive maturity, the relationship with productive maturity or lifetime productivity must be investigated before incorporating these traits in the total merit index. In addition, the genetic correlations of AFS or AC with the interval traits in first parity were positive, but those with the interval traits in second parity were negative. In this study, reproductive traits for a given parity were calculated for cows that have a calving date of next parity. For this reason, cows that had both reproductive records as heifers and for second parity were limited, so negative results were obtained.

The genetic correlations of same traits between first and second parity were very high (0.96 to 0.97 ), supporting the results of Haile-Mariam et al. (2003) who reported genetic correlation of calving interval between first and second parity as 0.88 . On the other hand, the phenotypic correlations of reproductive traits between different parities were generally low $(-0.07$ to 0.14$)$. In particular, the phenotypic correlations between heifer and cow traits were very low $(-0.06$ to 0.05$)$. Therefore, observations of reproductive traits in a given parity would not be a criterion for those in later parity. Conversely, even if observed reproductive performances for a given parity were poor, those in later parities could be recovered by better reproduction management practices.

\section{Relationships Between Yield and Reproductive Traits}

Tables 6 and 7 show genetic and phenotypic correlations between reproductive and yield traits, respectively. Also, residual correlations were calculated, and in across-parity analyses, these correlations were generally $<0.1$ in absolute value, but moderate residual correlations (around 0.3) were obtained between AC and yield traits for first parity, partly because the effect of age was not separated out completely.

The estimated genetic correlations were 0.33 to 0.50 between interval and yield traits, and -0.17 to -0.35 between $\mathrm{CR}$ in cows and yield traits, which were antagonistic and similar to previously reported estimates (Dematawewa and Berger, 1998; Haile-Mariam et al., 2003; Kadarmideen et al., 2003; Andersen-Ranberg et al., 2005; Abe et al., 2008). Judging from the heritabilities and data availability, reproductive traits in cows seem to be suitable for selection purposes, but these relationships suggest that intense selection by such traits would result in the deterioration of yield traits. This is unacceptable for farmers, so such selection would be difficult to perform at this time. Therefore, to improve reproductive performance, it is necessary to bring about changes in attitudes of the farmers, by stressing the economic benefits. The optimum balance of better reproduction and milk production should be examined. 
Table 6. Genetic correlations between reproductive and yield traits, ${ }^{1}$ with posterior standard deviations in parentheses

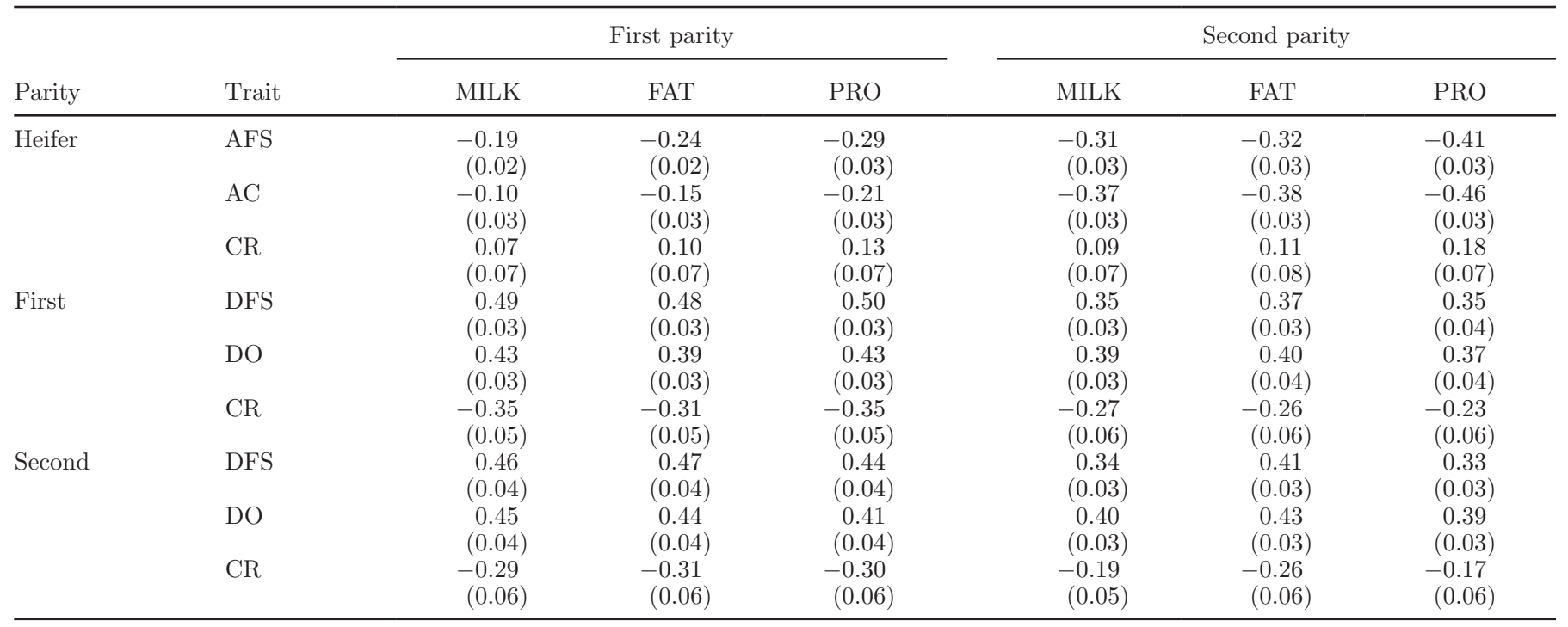

${ }^{1} \mathrm{AFS}=$ age at first service; $\mathrm{AC}=$ age at conception; $\mathrm{CR}=$ conception rate for first service; $\mathrm{DFS}=$ days from calving to first service; $\mathrm{DO}=$ days open; MILK $=305$-d milk yield; FAT $=305$-d fat yield; PRO $=305$-d protein yield.

Meanwhile, the genetic correlations ranged from -0.10 to -0.46 between AFS or AC with yield traits, and 0.07 to 0.18 between CR in heifers and yield traits, which were slightly desirable. The genetic correlations of AFS with yield traits in first parity were higher in absolute value than those of $\mathrm{AC}$ with yield traits in first parity, but opposite results were obtained in second parity. These results indicate that the relationship of AFS with early productive maturity would be stronger than that of AC. Andersen-Ranberg et al. (2005) estimated genetic correlation between nonreturn rate in heifers and protein yield in first parity as 0.04, and Muir et al. (2004) estimated genetic correlation between nonreturn rate in heifers and milk yield as 0.12 . The results in this study support their findings, but Kuhn et al. (2006) reported opposite results with an estimated genetic cor- relation between CR in heifers and milk yield of -0.19 . This difference is partly caused by the short period of data accumulation in the United States. The genetic correlations in this study imply that reproductive traits in heifers will improve reproductive performance without a loss in genetic progress for the yield traits.

The phenotypic correlations between reproductive and yield traits were -0.16 to 0.17 , which were lower in absolute value than the genetic correlations, and were similar to Dematawewa and Berger (1998) and Muir et al. (2004). The low phenotypic correlations suggest that high- and low-production cows are treated equally for reproduction management practices. As discussed previously, favorable reproductive outcome of the highyielding cows may be achieved through proper management.

Table 7. Phenotypic correlations ${ }^{1}$ between reproductive and yield traits $^{2}$

\begin{tabular}{|c|c|c|c|c|c|c|c|}
\hline \multirow[b]{2}{*}{ Parity } & \multirow[b]{2}{*}{ Trait } & \multicolumn{3}{|c|}{ First parity } & \multicolumn{3}{|c|}{ Second parity } \\
\hline & & MILK & FAT & PRO & MILK & FAT & PRO \\
\hline Heifer & $\mathrm{CR}$ & -0.06 & -0.06 & -0.05 & 0.02 & 0.02 & 0.01 \\
\hline \multirow{2}{*}{ First } & DFS & 0.11 & 0.10 & 0.10 & 0.07 & 0.06 & 0.05 \\
\hline & DO & 0.17 & 0.16 & 0.16 & 0.16 & 0.15 & 0.11 \\
\hline & $\mathrm{DO}$ & 0.07 & 0.07 & 0.05 & 0.17 & 0.16 & 0.16 \\
\hline & $\mathrm{CR}$ & -0.05 & -0.05 & -0.04 & -0.16 & -0.16 & -0.16 \\
\hline
\end{tabular}

${ }^{1}$ All posterior standard deviations were $<0.01$.

${ }^{2} \mathrm{AFS}=$ age at first service; $\mathrm{AC}=$ age at conception; $\mathrm{CR}=$ conception rate for first service; $\mathrm{DFS}=$ days from calving to first service; $\mathrm{DO}=$ days open; MILK $=305$-d milk yield; FAT $=305$-d fat yield; PRO $=305-$ d protein yield. 


\section{CONCLUSIONS}

The heritabilities of reproductive traits were generally low, suggesting low efficiency of genetic improvement by direct selection. Incorporating reproductive traits into the total merit index will partly diminish deterioration in genetic potential of reproduction. The estimated heritabilities and early availability of data suggests that DFS might be favorable in genetic selection for reproductive traits. However, the genetic correlations between DFS and yield traits were antagonistic, so it is difficult to assign considerable weight to DFS in the total merit index at this time. The genetic correlations between reproductive traits in heifers and reproductive or yield traits in cows were slightly desirable. However, the reporting rate of insemination records in heifers is much lower than that in cows. Additionally, if the genetic relationships with productive maturity are not considered, selection for reproductive traits in heifers may lead to the tendency of cows maturing earlier. Therefore, depending on the reporting rate of insemination records for heifers and the genetic relationship with early productive maturity, selection by reproductive traits in heifers will enable the improvement of reproductive performance without a loss in genetic progress for the yield traits.

\section{ACKNOWLEDGMENTS}

We are grateful to the Hokkaido Dairy Milk and Testing Association for providing insemination and lactation records and the Holstein Cattle Association of Japan, Hokkaido Branch for providing Holstein pedigree information. This study was supported in part by a grant from Global COE Program from Japanese Ministry of Education, Science, Sports, Culture and Technology.

\section{REFERENCES}

Abe, H., Y. Masuda, and M. Suzuki. 2008. Genetic relationships of age at first calving, and reproductive traits of cows and yield traits for Holsteins in Hokkaido. Nihon Chikusan Gakkaiho 79:203-209.

Andersen-Ranberg, I. M., G. Klemetsdal, B. Heringstad, and T. Steine. 2005. Heritabilities, genetic correlations, and genetic change for female fertility and protein yield in Norwegian dairy cattle. J. Dairy Sci. 88:348-355.

Atagi, Y., and K. Hagiya. 2005. Preliminary study of genetic evaluation for female fertility in Japan. Interbull Bull. 33:51-54.

Dematawewa, C. M. B., and P. J. Berger. 1998. Genetic and phenotypic parameters for 305-day yield, fertility, and survival in Holsteins. J. Dairy Sci. 81:2700-2709.

Haile-Mariam, M., P. J. Bowman, and M. E. Goddard. 2003. Genetic and environmental relationship among calving interval, survival, persistency of milk yield and somatic cell count in dairy cattle. Livest. Prod. Sci. 80:189-200.

Hansen, L. B., A. E. Freeman, and P. J. Berger. 1983. Association of heifer fertility with cow fertility and yield in dairy cattle. J. Dairy Sci. 66:306-314.

Harville, D. A., and R. W. Mee. 1984. A mixed-model procedure for analyzing ordered categorical data. Biometrics 40:393-408.

International Bull Evaluation Service. 2008. Interbull routine genetic evaluation for female fertility traits, August 2008. http://wwwinterbull.slu.se/Female_fert/framesida-fert.htm Accessed Oct. 3, 2008 .

Jamrozik, J., J. Fatehi, G. J. Kistemaker, and L. R. Schaeffer. 2005. Estimates of genetic parameters for Canadian Holstein female reproduction traits. J. Dairy Sci. 88:2199-2208.

Kadarmideen, H. N., R. Thompson, M. P. Coffey, and M. A. Kossaibati. 2003. Genetic parameters and evaluations from single- and multiple-trait analysis of dairy cow fertility and milk production. Livest. Prod. Sci. 81:183-195.

Kuhn, M. T., J. L. Hutchison, and G. R. Wiggans. 2006. Characterization of Holstein heifer fertility in the United States. J. Dairy Sci. 89:4907-4920.

Muir, B. L., J. Fatehi, and L. R. Schaeffer. 2004. Genetic relationships between persistency and reproductive performance in first-lactation Canadian Holsteins. J. Dairy Sci. 87:3029-3037.

National Livestock Breeding Center. 2007. Bulletin of the dairy sire and cow evaluation. No. 27. National Livestock Breeding Center, Fukushima, Japan.

Oikawa, T., and K. Sato. 1997. Treating small herds as fixed or random in an animal model. J. Anim. Breed. Genet. 114:177-183.

Tsuruta, S., and I. Misztal. 2006. THRGIBBS1F90 for estimation of variance components with threshold-linear models. Commun. 27-31 in Proc. 8th World Congr. Genet. Appl. Livest. Prod., Belo Horizonte, Brazil. 